\title{
Relative Toxicity of Leaf Extracts of Eucalyptus globulus and Centella asiatica against Mosquito Vectors Aedes aegypti and Anopheles stephensi
}

\author{
Savitha Sekhar Nair, Vinaya Shetty, and Nadikere Jaya Shetty \\ Centre for Applied Genetics, Bangalore University, J. B. Campus, Bengaluru, Karnataka 560056, India \\ Correspondence should be addressed to Nadikere Jaya Shetty; shetty_nj@yahoo.co.in
}

Received 17 July 2014; Accepted 1 October 2014; Published 22 October 2014

Academic Editor: José A. Martinez-Ibarra

Copyright ( 2014 Savitha Sekhar Nair et al. This is an open access article distributed under the Creative Commons Attribution License, which permits unrestricted use, distribution, and reproduction in any medium, provided the original work is properly cited.

\begin{abstract}
The larvicidal activity of different solvent leaf extracts (hexane, diethyl ether, dichloromethane, and methanol) of Eucalyptus globulus and Centella asiatica against two geographically different strains of Aedes aegypti and Anopheles stephensi was investigated. The extracts were tested against the late third instar larvae of Aedes aegypti and Anopheles stephensi, and larval mortality was observed after 24 hours of treatment. $\mathrm{LC}_{50}$ and $\mathrm{LC}_{90}$ were calculated. The $\mathrm{LC}_{50}$ values of hexane extract of Eucalyptus globulus against the late third instar larvae of the BSN and JPN strains of Aedes aegypti and the DLC and KNG strains of Anopheles stephensi were 225.2, 167.7, 118.8, and $192.8 \mathrm{ppm}$, while those of the hexane extract of Centella asiatica were 246.5, 268.7, 50.6, and $243.5 \mathrm{ppm}$, respectively. The $\mathrm{LC}_{50}$ values of diethyl ether extract of Centella asiatica were 339.6, 134.5, 241, and $14.7 \mathrm{ppm}$. The hexane extracts of both plants and the diethyl ether extract of C. asiatica presented the highest potential for the control of Aedes aegypti and Anopheles stephensi. The present findings also reveal the necessity of assaying multiple strains of a species to fully comprehend the larvicidal efficacy of a compound.
\end{abstract}

\section{Introduction}

Apart from being a social nuisance, mosquitoes pose serious health threats to both men and animals considering that they are the principal vectors for many vector borne diseases including malaria, dengue, yellow fever, and Chikungunya [1, 2] in men and equine encephalitis, haemorrhagic septicaemia of buffaloes, and enzootic hepatitis in animals [3]. In some individuals, mosquito bites also result in acute systemic allergic reactions defined by the presence of one or more of the following: urticaria, angioedema, wheezing, dyspnea, hypotension, and decrease or loss of consciousness [4]. The mosquito, Aedes (Stegomyia) aegypti (Linn.), (Diptera: Culicidae) is the primary vector of dengue, yellow fever, and Chikungunya [2]. According to WHO, over $40 \%$ of the world's population is now at risk of dengue and there are 200000 estimated cases of yellow fever, causing 30000 deaths, worldwide each year. Malaria, on the other hand, a life threatening disease which caused an estimated 627000 deaths in 2012 is transmitted exclusively through the bites of Anopheles mosquitoes [5]. Anopheles stephensi Liston (Diptera: Culicidae) is a major vector in India as well as in some of the West Asian countries and has been shown to be directly responsible for about $40-50 \%$ of the annual malarial incidence $[6,7]$.

Mosquito control is an extensively researched topic considering that presently we do not have vaccines for malaria and dengue $[8,9]$ and, therefore it becomes necessary to check the spread of these diseases. Vector control methods, thus are of utmost prominence. The incessant use of chemical insecticides has often led to the disruption of natural biological control system and outbreak of insect species [10]. The selective pressure of conventional insecticides is enhancing the resistance of mosquito strains at an alarming rate [11], increasing the demand for new products that are eco-friendly, target-specific, and biodegradable. Plant-derived insecticides provide an alternative to synthetic pesticides because of their generally low environmental pollution, low toxicity to men, and other advantages [12]. 
Earlier studies have shown the efficacy of Eucalyptus oils as a larvicide against mosquitoes [13-16]. In the year 2004, Yang et al. reported that Eucalyptus leaf oil, particularly some of its components such as 1,8-cineole, 1- $\alpha$-terpineol, and (E)pinocaveol, merits further study as lead compounds for the control of the human hair louse, Pediculus humanus capitis De Geer (Pediculidae) [17]. Constituents of the essential oil of Eucalyptus camaldulensis Dehnh and Eucalyptus urophylla S. T. Blake (Myrtaceae) a-phellandrene, limonene, p-cymene, c-terpinene, terpinolene, and a-terpinene have been shown to possess strong larvicidal effects against Aedes aegypti and Aedes albopictus [15]. The various components of Eucalyptus essential oil have been shown to act synergistically (and not additively) to bring the overall bactericidal activity [18].

Centella asiatica is mostly studied for its medicinal properties. Very few studies have documented its potential as a biopesticide. A study has suggested that the leaf extract of C. asiatica is promising as a larvicide and adult emergence inhibitor against Culex quinquefasciatus Say (Culicidae) [19]. Shukla et al. [20] isolated and studied the growth inhibitory effect of $2 \alpha, 3 \beta, 6 \beta, 23-\alpha$ tetrahydroxyurs-12-ene-28-oic acid, a triterpenoid glycoside against larvae of Spilarctia obliqua Walker (Arctiidae).

Numerous studies have examined the variations in larvicidal efficacies of plant extracts tested against different mosquito species; however, we were not able to find any reports of the larvicidal efficacies of plant extracts tested against different strains of mosquitoes of the same species. Susceptibility studies involving strains from different locations could be beneficial to gauge the efficacy of the drug being studied and as a prelude to investigations involving the inherent resistance mechanisms of the vectors to the drugs.

Different solvent types can significantly affect the potency of the extracted plant compounds and there is a difference in the chemoprofile of the plant species [21]. This is because polar solvents extract polar constituents of the plant, while nonpolar solvents extract the nonpolar constituents of the plant. Hence, the best results will be observed using the plant extract of the solvent whose polarity matches that of the molecules in the plant responsible for insecticidal activity (if any). Additionally, extracts or pure compounds derived from specific solvents can influence the bioactivity, probably because of the active components which are present in large quantities [22].

In the present study, we have investigated the larvicidal activity of the hexane, diethyl ether, dichloromethane, and methanol extracts of the leaves of Eucalyptus globulus Labill (Myrtaceae) and Centella asiatica (Linn.) Urban (Apiaceae) against two geographically different strains of Aedes (Stegomyia) aegypti (Linn.) (Diptera: Culicidae) and Anopheles stephensi Liston (Diptera: Culicidae).

\section{Materials and Methods}

2.1. Mosquito Culture. Four strains which consisted of laboratory colonies of Aedes aegypti collected from J. P. Nagar (JPN) $\left(12.9120^{\circ} \mathrm{N} ; 77.5930^{\circ} \mathrm{E}\right)$ and Basaveshwaranagar (BSV) $\left(12.9867^{\circ} \mathrm{N} ; 77.5386^{\circ} \mathrm{E}\right)$ and Anopheles stephensi collected from Dollars Colony (DLC) $\left(13^{\circ} 2^{\prime} 30^{\prime \prime} \mathrm{N} ; 77^{\circ} 34^{\prime} 3^{\prime \prime} \mathrm{E}\right)$ and
Kengeri $(\mathrm{KNG})\left(12.9100^{\circ} \mathrm{N} ; 77.4800^{\circ} \mathrm{E}\right)$ were used for this study. Larvae collected from the said locations of BBMP region, Karnataka, India, during the months March-April 2012, had been reared continuously in the insectary at the Centre for Applied Genetics, Bangalore University, following the method of Shetty [23].

2.2. Collections of Plant Materials. The leaves of Eucalyptus globulus and Centella asiatica were collected from Bangalore city $\left(11^{\circ} 1^{\prime} 48^{\prime \prime} \mathrm{N} ; 77^{\circ} 2^{\prime} 36^{\prime \prime} \mathrm{E}\right.$; elevation: $\left.399 \mathrm{~m}\right)$, Karnataka, India, in July 2013, and were authenticated at the Department of Botany, Bangalore University, Bangalore, India.

2.3. Preparation of Plant Extracts. The leaves ( $2 \mathrm{~kg}$ each) were air dried in shade for 15-30 days. The dried leaves were then powdered mechanically using a commercial electrical stainless steel blender. One $\mathrm{kg}$ of powdered leaves was extracted successively by maceration using nonpolar to polar solvents, namely, hexane, diethyl ether, dichloromethane, and methanol. In each solvent, the plant material was soaked for $48 \mathrm{~h}$ at $35^{\circ} \mathrm{C}$ and filtered twice using Whatman number 1 filter paper to obtain the extract, and to the residue the same solvent was added again. The procedure was repeated twice to obtain maximum extract. The extracts were concentrated at reduced temperature using a rotary vacuum evaporator and stored at a temperature of $4^{\circ} \mathrm{C}$. One gram of the concentrated plant extract was dissolved in $100 \mathrm{~mL}$ of $1: 1$ acetone : dimethyl sulfoxide (DMSO) and considered as $1 \%$ stock solution. From this stock solution, varying concentrations of each extract was prepared and these solutions were used for larvicidal bioassay. All chemicals used in this study were of extra pure grade and were obtained from Sisco Research Laboratories PVT. Ltd., India.

2.4. Larvicidal Bioassay. Larvicidal activity of each extract derived from the leaves of Eucalyptus globulus and Centella asiatica against the two strains of Ae. aegypti and An. stephensi was assessed by using a slightly modified version of the WHO standard method [24].

Initially, the mosquito larvae were exposed to a broad range of test concentrations to determine the activity range of each extract. Based on the results of preliminary screening, batches of 25 late third instar larvae were added to $300 \mathrm{~mL}$ wide mouth disposable bowls containing serial concentrations (6-9 concentrations, yielding between 10\% and 95\% mortality in $24 \mathrm{hrs}$ ) of each plant extract made up to $250 \mathrm{~mL}$ by volume using tap water. The test was carried at a temperature of $25 \pm 2^{\circ} \mathrm{C}$ and relative humidity of $75 \pm 5 \%$. The numbers of dead larvae were counted after 24 hours of exposure and percentage mortality was calculated for each test as follows:

\section{Percentage Mortality}

$$
=\frac{\text { Number of dead larvae/pupae }}{\text { Number of larvae introduced }} \times 100 \text {. }
$$

The final percentage mortality was calculated from the average of three replicates. Solutions containing tap water and $1: 1$ acetone : dimethyl sulfoxide, but without the plant sample, 
served as controls. The control mortalities were corrected by using Abbott's formula [25].

2.5. Statistical Analysis. The average larval mortality data were subjected to probit analysis for calculating $\mathrm{LC}_{50}$ and $\mathrm{LC}_{90}$ and other statistics at 95\% fiducial limits of upper confidence limit (UCL) and lower confidence limit (LCL), and Chi-square values were calculated using the SPSS 12.0 (Statistical Package of Social Sciences) software (Finney, 1971). The Chi-square values were considered significant at $P<0.05$ level.

\section{Results}

The larvicidal efficacies of hexane, diethyl ether, dichloromethane, and methanol extracts of both Eucalyptus globulus and Centella asiatica were established for two different mosquito strains of each of the above said species from the Bangalore, Karnataka. The data were recorded and statistical data including regression equation, $\mathrm{LC}_{50}, \mathrm{LC}_{90}$, LCL, UCL, and Chi-square values were calculated and presented (Table 1). No mortality was observed in the control.

All plant extracts showed varied level of toxic effects with species after 24 hours of exposure, while the methanol extract demonstrated very low larvicidal efficacy in the case of both of the plants.

3.1. Eucalyptus globulus. Among the An. stephensi strains, the DLC strain displayed the highest susceptibility to the hexane extract ( $\mathrm{LC}_{50} 118.8$ and $\mathrm{LC}_{90} 450.4 \mathrm{ppm}$ ) followed by the diethyl ether extract ( $\mathrm{LC}_{50} 464.1$ and $\left.\mathrm{LC}_{90} 800.1 \mathrm{ppm}\right)$. The KNG strain of Anopheles stephensi, on the other hand, showed the highest larval mortality in the dichloromethane extract ( $\mathrm{LC}_{50} 162.0$ and $\mathrm{LC}_{90} 582.4 \mathrm{ppm}$ ), followed by the hexane extract ( $\mathrm{LC}_{50} 192.8$ and $\left.\mathrm{LC}_{90} 827 \mathrm{ppm}\right)$. The BSN and JPN strains of Ae. aegypti were most susceptible to the hexane extract ( $\mathrm{LC}_{50} 225.2,167.7$ and $\mathrm{LC}_{90} 423.6,304.0 \mathrm{ppm}$, resp.). The methanol extract was the least effective in all cases. A higher level of tolerance was recorded in the BSN strain of $A$ e. aegypti to the methanol extract $\left(\mathrm{LC}_{50} 1839.0\right.$ and $\mathrm{LC}_{90}$ $3235.9 \mathrm{ppm})$.

3.2. Centella asiatica. The hexane extract produced the highest mortality in the case of the BSN and JPN strains of Ae. aegypti $\left(\mathrm{LC}_{50} 246.5,268.7\right.$ and $\mathrm{LC}_{90}$ 593.1, $1606.8 \mathrm{ppm}$, resp.), and also the DLC strain of An. stephensi $\left(\mathrm{LC}_{50} 50.6\right.$ and $\mathrm{LC}_{90}$ $328.8 \mathrm{ppm}$ ), the KNG strain of An. stephensi however was most susceptible to the diethyl ether extract ( $\mathrm{LC}_{50} 14.7$ and $\mathrm{LC}_{90} 118.0 \mathrm{ppm}$ ). Again, the methanol extract was the least potent in all cases. The BSN strain of Ae. aegypti displayed a higher level of tolerance ( $\mathrm{LC}_{50} 776.5$ and $\left.\mathrm{LC}_{90} 3853.4 \mathrm{ppm}\right)$ upon treatment with the methanol extract.

\section{Discussion}

The leaf extracts of Eucalyptus globulus and Centella asiatica showed an overall moderate larvicidal effect when tested against different strains of Ae. aegypti and An. stephensi.
Among the four extracts studied, the hexane extracts of both plants and the diethyl ether extract of $C$. asiatica demonstrated higher potential for the control of strains of mosquito vectors, followed by dichloromethane. The methanol extract produced a comparatively less promising result. The effect of the extracts on larval mortality was dose-dependent, with increasing rates of larval mortality observed at increasing concentrations. The highest level of tolerance was observed in the BSN strain of Ae. aegypti towards the methanol extract of E. globulus.

Although the larvicidal efficacy of the extracts is not as promising as that of synthetic insecticides commonly in use today [26], the present results are comparable to those of earlier authors who worked on various plant extracts as larvicides against different mosquito species. The methanol leaf extract of Clitoria ternatea L. (Leguminosae) showed a dose-dependent larvicidal activity against An. stephensi with an $\mathrm{LC}_{50}$ value of $555.6 \mathrm{ppm}$ [27]. In the case of Morinda citrifolia L. (Rubiaceae) the highest larvicidal activity was exhibited by the methanol extract of the leaf when compared to the hexane, chloroform, acetone, and water extracts; the $\mathrm{LC}_{50}$ in case of An. stephensi and Ae. aegypti was observed to be 261.96 and $277.92 \mathrm{ppm}$, respectively. The chloroform leaf extracts of Nyctanthes arbortristis L. (Oleaceae) demonstrated an $\mathrm{LC}_{50}$ value of $780.6 \mathrm{ppm}$, while the $\mathrm{LC}_{50}$ value of the methanol flower extract of the same plant was $679.4 \mathrm{ppm}$ when tested against An. stephensi. Studies have also been carried out on the larvicidal potential of the essential oil extracted from the Eucalyptus species [13-15] and E. globulus in particular [28]. However, this is the first time report of the larvicidal efficacy of serial extracts of Eucalyptus globulus and Centella asiatica leaves using multiple solvents against different geographical strains of Ae. aegypti and An. stephensi. In the present study, strains of both species of mosquitoes were found to be highly susceptible to hexane leaf extracts when compared to the other solvent extracts.

Numerous authors have observed a converse relationship between extract effectiveness and solvent polarity where the efficacy increases with decreasing polarity [29-32]. Singh et al. [33] reported the $\mathrm{LC}_{50}$ values of the hexane extract of Eucalyptus citriodora Hook (Myrtaceae) against the IVth instar larvae of An. stephensi (69.86 ppm) and Ae. aegypti (91.76 ppm). Hexane extracts of other plants have also shown similar satisfactory larvicidal potency. $\mathrm{LC}_{50}$ of hexane leaf extract of Citrus sinensis (L.) Osbeck (Rutaceae) against early fourth instars of Ae. aegypti was found to be $446.84 \mathrm{ppm}$ [34]. The $\mathrm{LC}_{50}$ of hexane leaf extract of Murraya koenigii (L.) Spreng (Rutaceae) against third instars Culex quinquefasciatus was found to be $963.53 \mathrm{ppm}$ [35]. In the case of Citrullus colocynthis (L.) Schrad (Cucurbitaceae), however, the $\mathrm{LC}_{50}$ of the hexane extract was found to be $1451.29 \mathrm{ppm}$ while that of the diethyl ether extract was found to be $503.39 \mathrm{ppm}$. This result is similar to that of the KNG strain of An. stephensi in our studies, where the diethyl ether extract of C. asiatica produced a better result than the hexane extract. Contrarily, the other An. stephensi strain that we worked with (DLC) exhibited higher susceptibility for the hexane extract against the diethyl ether extract. 


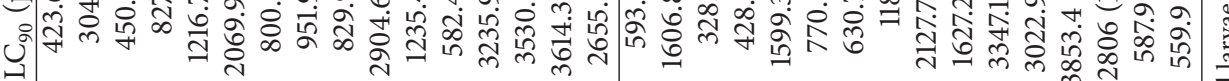


Even though our studies show methanol extracts to produce the least mortality, other plants such as Morinda citrifolia L. (Rubiaceae) and Erythrina indica Lam (Leguminosae) have been shown to produce greater susceptibility for their methanol extract when compared to their hexane extract $[36,37]$. Therefore, the present study suggests that, in the case of E. globulus and C. asiatica, the compounds majorly responsible for the insecticidal activity are most probably in the nonpolar and intermediate range and are not polar.

There is probably also the result of the synergistic activity of the active compounds that influences the efficacy of the extract, against the physiological characteristics of each strain tested. For instance, dichloromethane and diethyl ether are solvents with very similar polarity and should typically elute compounds of the same class, and the results show that in some instances dichloromethane extracts prove that they have higher efficacy, while diethyl ether extracts show greater potency. Further studies involving larger number of strains and purified isolated constituents should reveal a clearer picture of interaction between the bioactive molecules and target species.

In the present investigation, it was also interesting to note that the variation in the response of different strains of mosquito of the same species to a specific plant extract is almost the same as the variation in the response of different strains of mosquito of different species to the same extract. For instance, the $\mathrm{LC}_{50}$ values for diethyl ether extract of C. asiatica against the An. stephensi strains KGR and DLC are $14.7 \mathrm{ppm}$ and $241 \mathrm{ppm}$, while the $\mathrm{LC}_{50}$ values for the same extract against the Ae. aegypti strains JPN and BSV are 134.5 and $339.6 \mathrm{ppm}$. From this study, it is revealed that it is imperative to assay the extract against different geographical strains of the same species to ascertain the efficacy of a compound.

Earlier studies on different geographical strains of $A n$. stephensi and Ae. Aegypti have reported varied levels of susceptibility to various insecticides commonly used in mosquito vector control [26, 38-43]. Unlike conventional insecticides which are based on a single active ingredient, plant derived insecticides comprise botanical blends of chemical compounds which act concertedly on both behavioral and physiological processes. Thus, there is very little chance of pests developing resistance to such substances. Identifying bioinsecticides that are efficient, as well as being suitable and adaptive to ecological conditions, is imperative for continued effective vector control management [21]. In order to develop cost effective pesticides from the plant leaves used in the present study, it will be necessary to carry out further studies to determine the active compounds in these plants, their larvicidal efficacies, their individual and synergistic modes of action, the feasibility of large scale use, and stability of these active compounds under field conditions. Most studies using biological extracts have been tested against a single strain of a species. This is probably because one would not expect to observe large variations in the susceptibility of one strain to another. Unlike the varied resistance status observed in the case of synthetic insecticides, the biological extracts used in this study have not been used by municipal bodies as insecticides. Therefore, the observed variation in response between different strains does not appear to have been caused by such a selection event, but rather by the intervention of biological and genetic factors, resulting in the change in the susceptibility to different plant extracts.

\section{Conclusion}

In the present study, the hexane extracts of both plants and the diethyl ether extract of $C$. asiatica demonstrated the highest potential for the control of strains of mosquito vectors. The results indicate that the compounds responsible for the insecticidal activity of both plants are most probably in the nonpolar and intermediate range. Also, the present findings show that it is necessary to assay multiple strains of a species to fully comprehend the larvicidal efficacy of a compound.

\section{Conflict of Interests}

The authors declare that there is no conflict of interests regarding the publication of this paper.

\section{References}

[1] World Health Organization, "Vector control for malaria and other mosquito-borne diseases," WHO Technical Report 857, 1995.

[2] A. C. Morrison, E. Zielinski-Gutierrez, T. W. Scott, and R. Rosenberg, "Defining challenges and proposing solutions for control of the virus vector Aedes aegypti," PLoS Medicine, vol. 5, no. 3, article e68, 2008.

[3] S. Christophers, Aedes Aegypti (L.), The Yellow Fever Mosquito. Its Life History, Bionomics, and Structure, Cambridge University Press, London, UK, 1960.

[4] Z. Peng, A. N. Beckett, R. J. Engler, D. R. Hoffman, N. L. Ott, and F. E. R. Simons, "Immune responses to mosquito saliva in 14 individuals with acute systemic allergic reactions to mosquito bites," Journal of Allergy and Clinical Immunology, vol. 114, no. 5, pp. 1189-1194, 2004.

[5] World Health Organization, "Malaria factsheet\#94," 2014, http://www.who.int/mediacentre/factsheets/fs094/en/.

[6] C. F. Curtis, "Should DDT continue to be recommended for malaria vector control?" Medical and Veterinary Entomology, vol. 8, no. 2, pp. 107-112, 1994.

[7] F. H. Collins and S. M. Paskewitz, "Malaria: current and future prospects for control," Annual Review of Entomology, vol. 40, pp. 195-219, 1995.

[8] World Health Organization, Malaria Vaccine Rainbow Tables, World Health Organization, Geneva, Switzerland, 2013, http:// www.who.int/immunization/research/development/Rainbow_ tables/en/.

[9] World Health Organization, "Dengue and dengue hemorrhagic fever factsheet\#117," 2014, http://www.who.int/mediacentre/ factsheets/fs1l7/en/.

[10] U. Chaithong, W. Choochote, K. Kamsuk et al., "Larvicidal effect of pepper plants on Aedes aegypti (L.) (Diptera: Culicidae)," Journal of Vector Ecology, vol. 31, no. 1, pp. 138-144, 2006.

[11] A. W. Brown, "Insecticide resistance in mosquitoes: a pragmatic review," Journal of the American Mosquito Control Association, vol. 2, no. 2, pp. 123-140, 1986. 
[12] S. Liu, G. Shi, H. Cao, F. Jia, and X. Liu, "Survey of pesticidal component in plant," in Entomology in China in 21st Century, Proceedings of the Conference of Chinese Entomological Society, pp. 1098-1104, Science \& Technique Press, 2000.

[13] S. Senthil Nathan, "The use of Eucalyptus tereticornis Sm. (Myrtaceae) oil (leaf extract) as a natural larvicidal agent against the malaria vector Anopheles stephensi Liston (Diptera: Culicidae)," Bioresource Technology, vol. 98, no. 9, pp. 1856-1860, 2007.

[14] A. Lucia, L. W. Juan, E. N. Zerba, L. Harrand, M. Marcó, and H. M. Masuh, "Validation of models to estimate the fumigant and larvicidal activity of Eucalyptus essential oils against Aedes aegypti (Diptera: Culicidae)," Parasitology Research, vol. 110, no. 5, pp. 1675-1686, 2012.

[15] S.-S. Cheng, C.-G. Huang, Y.-J. Chen, J.-J. Yu, W.-J. Chen, and S.-T. Chang, "Chemical compositions and larvicidal activities of leaf essential oils from two eucalyptus species," Bioresource Technology, vol. 100, no. 1, pp. 452-456, 2009.

[16] S. M. Medhi, S. Reza, K. Mahnaz et al., "Phytochemistry and larvicidal activity of Eucalyptus camaldulensis against malaria vector, Anopheles stephensi," Asian Pacific Journal of Tropical Medicine, vol. 3, no. 11, pp. 841-845, 2010.

[17] Y.-C. Yang, H.-Y. Choi, W.-S. Choi, J. M. Clark, and Y.-J. Ahn, "Ovicidal and adulticidal activity of Eucalyptus globulus leaf Oil Terpenoids against Pediculus humanus capitis (Anoplura: Pediculidae)," Journal of Agricultural and Food Chemistry, vol. 52, no. 9, pp. 2507-2511, 2004.

[18] K. Cimanga, K. Kambu, L. Tona et al., "Correlation between chemical composition and antibacterial activity of essential oils of some aromatic medicinal plants growing in the Democratic Republic of Congo," Journal of Ethnopharmacology, vol. 79, no. 2, pp. 213-220, 2002.

[19] S. Rajkumar and A. Jebanesan, "Larvicidal and adult emergence inhibition effect of Centella asiatica Brahmi (Umbelliferae) against mosquito Culex quinquefasciatus say (Diptera: Culicidae)," African Journal of Biomedical Research, vol. 8, no. 1, pp. 31-33, 2006.

[20] Y. N. Shukla, R. Srivastava, A. K. Tripathi, and V. Prajapati, "Characterization of an ursane triterpenoid from Centella asiatica with growth inhibitory activity against Spilarctia obliqua," Pharmaceutical Biology, vol. 38, no. 4, pp. 262-267, 2000.

[21] A. Ghosh, N. Chowdhury, and G. Chandra, "Plant extracts as potential mosquito larvicides," Indian Journal of Medical Research, vol. 135, no. 5, pp. 581-598, 2012.

[22] P. V. Oliveira, J. C. Ferreira Jr., F. S. Moura et al., "Larvicidal activity of 94 extracts from ten plant species of northeastern of Brazil against Aedes aegypti L. (Diptera: Culicidae)," Parasitology Research, vol. 107, no. 2, pp. 403-407, 2010.

[23] N. J. Shetty, "Chromosomal translocations and semisterility in the malaria vector Anopheles fluviatilis James," Indian Journal of Malariology, vol. 20, pp. 45-48, 1983.

[24] World Health Organization, "Instructions for determining the susceptibility or resistance of mosquito larvae to insecticides," Tech. Rep. WHO/VBC/81.807, World Health Organization, Geneva, Switzerland, 1981.

[25] W. S. Abbott, "A Method of computing the effectiveness of an insecticide," Journal of Economic Entomology, vol. 18, no. 2, pp. 265-267, 1925.

[26] V. Shetty, D. Sanil, and N. J. Shetty, "Insecticide susceptibility status in three medically important species of mosquitoes, Anopheles stephensi, Aedes aegypti and Culex quinquefasciatus, from Bruhat Bengaluru Mahanagara Palike, Karnataka, India," Pest Management Science, vol. 69, no. 2, pp. 257-267, 2013.

[27] N. Mathew, M. G. Anitha, T. S. L. Bala, S. M. Sivakumar, R. Narmadha, and M. Kalyanasundaram, "Larvicidal activity of Saraca indica, Nyctanthes arbor-tristis, and Clitoria ternatea extracts against three mosquito vector species," Parasitology Research, vol. 104, no. 5, pp. 1017-1025, 2009.

[28] B. Selamawit and R. Nagappan, "Evaluation of water and ethanol extract of Eucalyptus globulus labillardiere (Myrtaceae) leaves against immature stages of filarial vector Culex quinquefasciatus say (Diptera: Culicidae)," Current Research Journal of Biological Sciences, p. 4, 2012.

[29] A.-A. Aivazi and V. A. Vijayan, "Larvicidal activity of oak Quercus infectoria Oliv. (Fagaceae) gall extracts against Anopheles stephensi Liston," Parasitology Research, vol. 104, no. 6, pp. 12891293, 2009.

[30] G. Sharma, H. Kapoor, M. Chopra, K. Kumar, and V. Agrawal, "Strong larvicidal potential of Artemisia annua leaf extract against malaria (Anopheles stephensi Liston) and dengue (Aedes aegypti L.) vectors and bioassay-driven isolation of the marker compounds," Parasitology Research, vol. 113, no. 1, pp. 197-209, 2014.

[31] M. S. Mulla and T. Su, "Activity and biological effects of neem products against arthropods of medical and veterinary importance," Journal of the American Mosquito Control Association, vol. 15, no. 2, pp. 133-152, 1999.

[32] K. P. Prathibha, B. S. Raghavendra, and V. A. Vijaya, "Evaluation of larvicidal effect of Euodia ridleyi Hochr. Leaf extract against three mosquito species at Mysore," Research Journal of Biological Sciences, vol. 5, no. 6, pp. 452-455, 2010.

[33] R. K. Singh, R. C. Dhiman, and P. K. Mittal, "Studies on mosquito larvicidal properties of Eucalyptus citriodora Hook (Family: Myrtaceae)," Journal of Communicable Diseases, vol. 39, no. 4, pp. 233-236, 2007.

[34] R. Warikoo, A. Ray, J. K. Sandhu, R. Samal, N. Wahab, and S. Kumar, "Larvicidal and irritant activities of hexane leaf extracts of Citrus sinensis against dengue vector Aedes aegypti L," Asian Pacific Journal of Tropical Biomedicine, vol. 2, no. 2, pp. 152-155, 2012.

[35] K. Kovendan, S. Arivoli, R. Maheshwaran, K. Baskar, and S. Vincent, "Larvicidal efficacy of Sphaeranthus indicus, Cleistanthus collinus and Murraya koenigii leaf extracts against filarial vector, Culex quinquefasciatus say (Diptera: Culicidae)," Parasitology Research, vol. 111, no. 3, pp. 1025-1035, 2012.

[36] K. Kovendan, K. Murugan, S. P. Shanthakumar, S. Vincent, and J.-S. Hwang, "Larvicidal activity of Morinda citrifolia L. (Noni) (Family: Rubiaceae) leaf extract against Anopheles stephensi, Culex quinquefasciatus, and Aedes aegypti," Parasitology Research, vol. 111, no. 4, pp. 1481-1490, 2012.

[37] M. Govindarajan and R. Sivakumar, "Larvicidal, ovicidal, and adulticidal efficacy of Erythrina indica (Lam.) (Family: Fabaceae) against Anopheles stephensi, Aedes aegypti, and Culex quinquefasciatus (Diptera: Culicidae)," Parasitology Research, vol. 113, no. 2, pp. 777-791, 2014.

[38] A. Ponlawat, J. G. Scott, and L. C. Harrington, "Insecticide susceptibility of Aedes aegypti and Aedes albopictus across Thailand," Journal of Medical Entomology, vol. 42, no. 5, pp. 821825, 2005.

[39] S. C. Rawlins, "Spatial distribution of insecticide resistance in Caribbean populations of Aedes aegypti and its significance," Revista Panamericana de Salud Pública, vol. 4, no. 4, pp. 243251, 1998. 
[40] G. Albrieu Llinás, E. Seccacini, C. N. Gardenal, and S. Licastro, "Current resistance status to temephos in Aedes aegypti from different regions of Argentina," Memorias do Instituto Oswaldo Cruz, vol. 105, no. 1, pp. 113-116, 2010.

[41] P. Baskar and N. J. Shetty, "Susceptibility status of Anopheles stephensi Liston to insecticides," Journal of Communicable Diseases, vol. 24, no. 3, pp. 188-190, 1992.

[42] C. Ghosh, B. Rajashree, B. Priyalakshmi, and N. J. Shetty, "Susceptibility status of different strains of Anopheles stephensi Liston to fenitrothion, deltamethrin and cypermethrin," Pestology, vol. 26, no. 4, pp. 47-52, 2002.

[43] N. J. Shetty, T. Zin, T. P. N. Hariprasad, and M. Z. Minn, "Insecticide susceptibility studies in thirty strains of Anopheles stephensi Liston-a malaria vector to alphamethrin, bifenthrin (synthetic pyrethroids) and neem (a botanical insecticide)," Pestology, vol. 30, no. 10, pp. 21-28, 2006. 

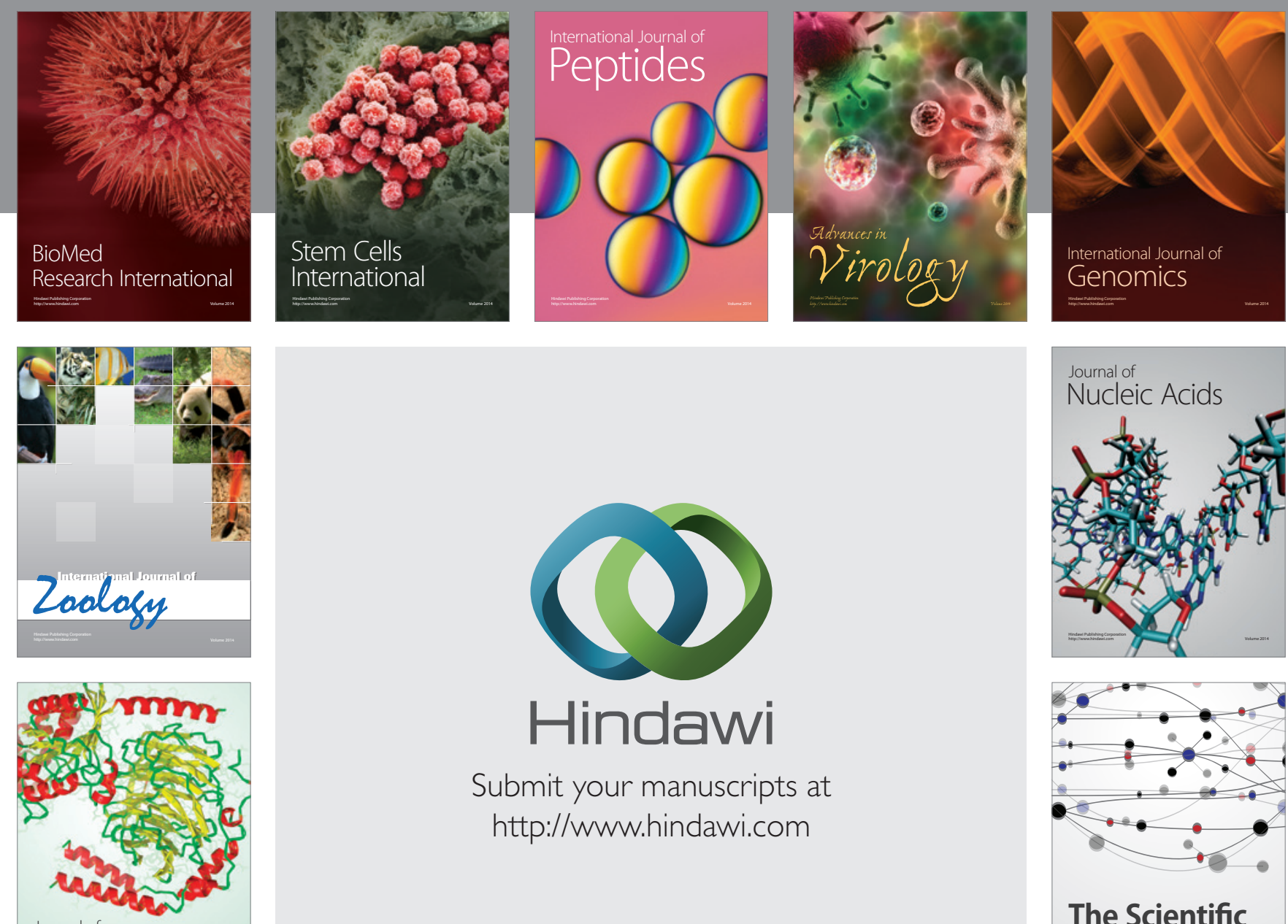

Submit your manuscripts at

http://www.hindawi.com

Journal of
Signal Transduction
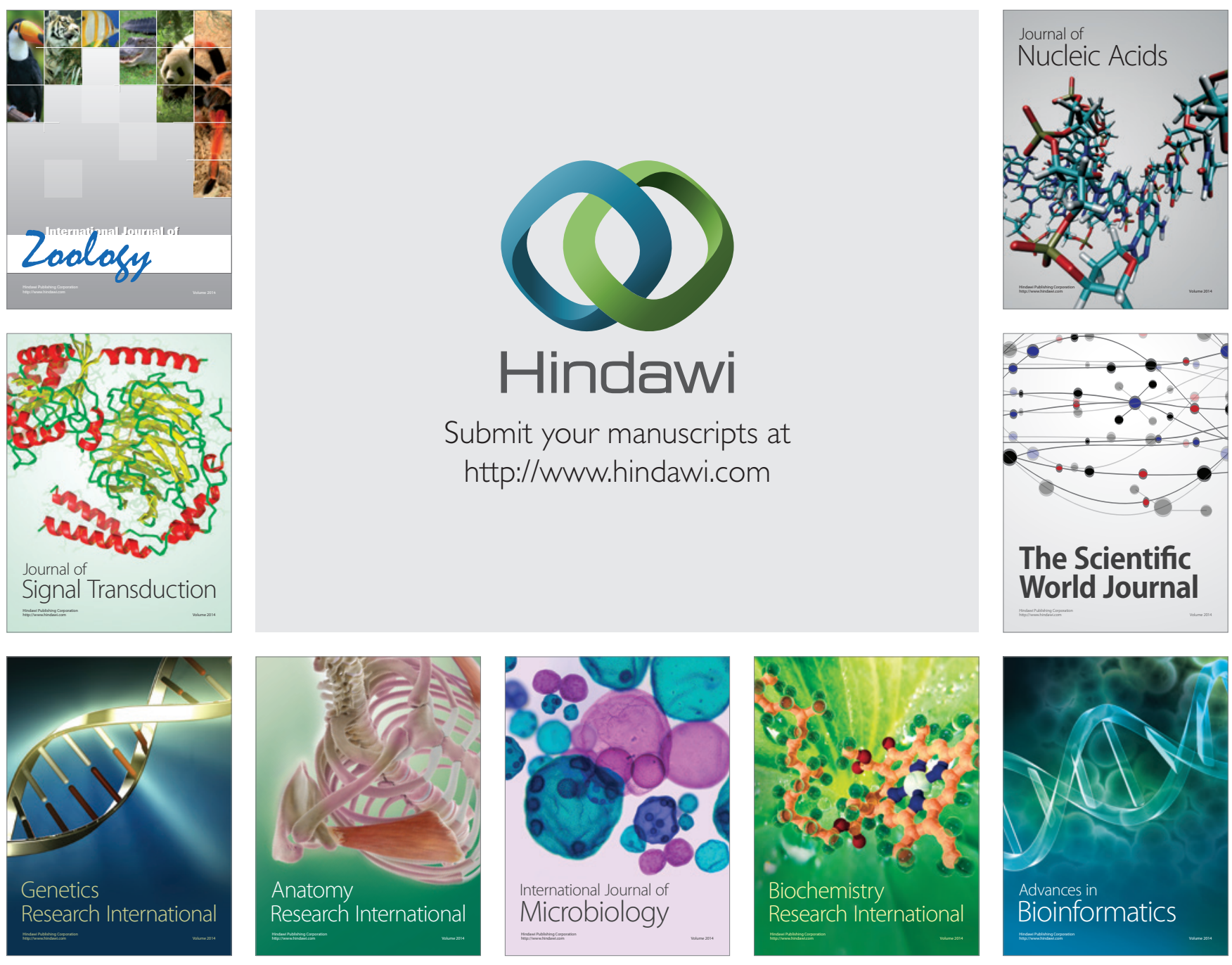

The Scientific World Journal
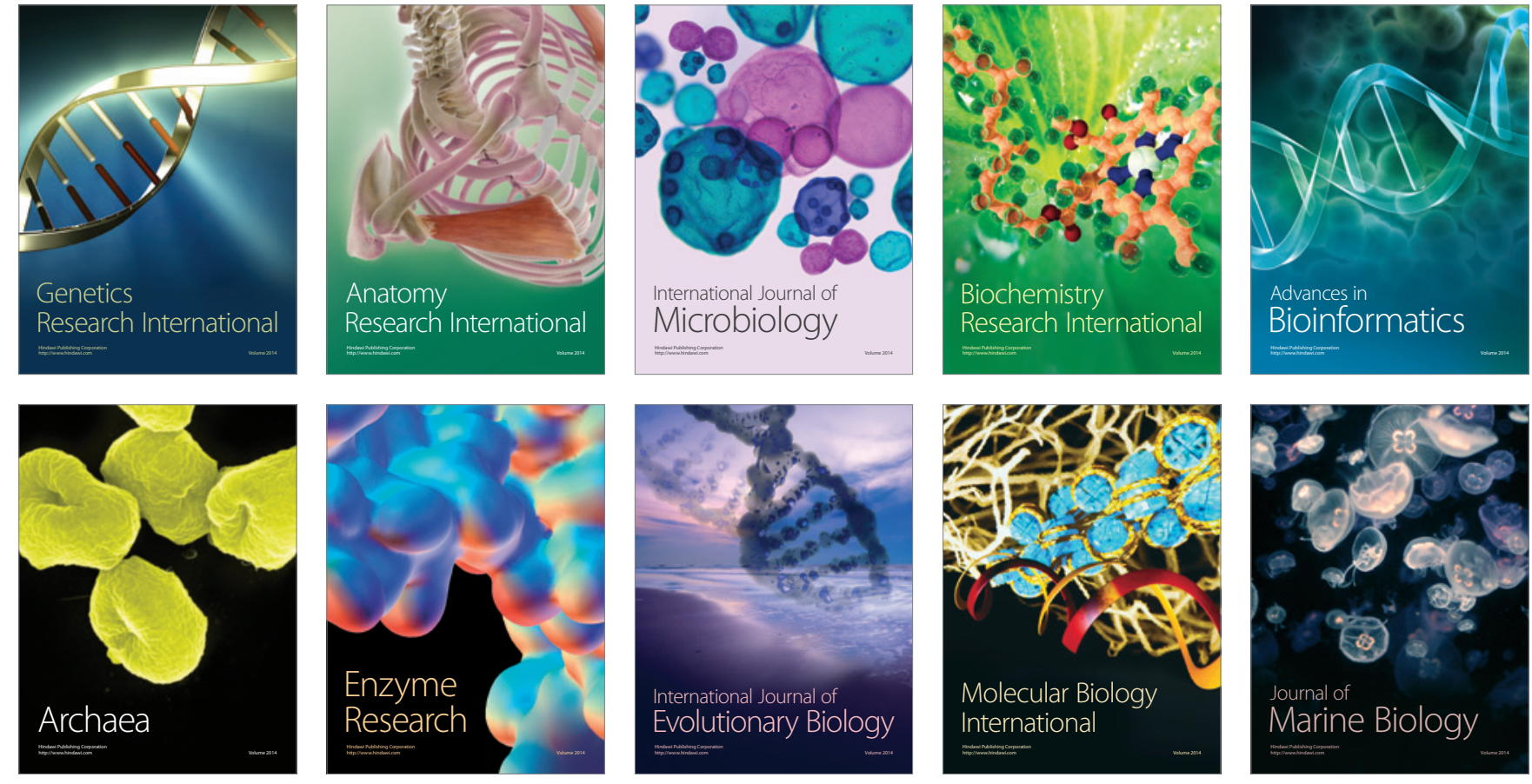